\title{
Survey of ethical dilemmas facing intensivists in South Africa in the admission of patients with HIV infection requiring intensive care
}

\author{
K Naidoo, ${ }^{1}$ MB ChB, MMed (FamMed), LLM (Medical Law); J A Singh, ${ }^{2}$ BA, LLB, LLM, MHSc, PhD; \\ U G Lalloo, ${ }^{3}$ MB ChB, FCP, MD, DOH, FCCP, FRCP
}

\author{
${ }^{1}$ Department of Family Medicine, School of Nursing and Public Health, Nelson R Mandela School of Medicine, University of KwaZulu-Natal, Durban, \\ South Africa \\ ${ }^{2}$ Centre for the AIDS Programme of Research in South Africa (CAPRISA), Doris Dukes Medical Centre Research Institute and Nelson R Mandela School \\ of Medicine, University of KwaZulu-Natal, Durban, South Africa \\ ${ }^{3}$ Department of Pulmonology and Critical Care, School of Clinical Medicine, Nelson R Mandela College of Medicine, University of KwaZulu-Natal, \\ Durban, South Africa
}

Corresponding author:U G Lalloo (umeshlalloo@gmail.com)

Background. Maturing of the burgeoning HIV epidemic in South Africa has resulted in an increased demand for intensive care. Objectives. To investigate the influence of ethical dilemmas facing South African intensivists on decisions about access to intensive care for patients with HIV infection in resource-limited settings.

Methods. A cross-sectional, descriptive, quantitative, analytical, anonymous attitudes-and-perception questionnaire survey of 90 intensivists. The main outcome measure was the rating of factors influencing decisions on admission to intensive care and responses to 5 hypothetical clinical scenarios.

Results. The number of intensivists who considered the prognosis of the acute disease and of the underlying disease to be most important was $87.9 \%$ ( $n=74)$. Most $(71.6 \% ; n=63)$ intensivists cited availability of an intensive care unit (ICU) bed as influencing the decision to admit. Intensivists comprising $26.8 \%(n=22)$ of the total group rated as probably important or least important the 'resources available'; 'bed used to the prejudice of another patient' was stated by $16.4 \%(n=14)$; and 'policy of the intensive care unit' by $17 \%(n=14)$. Nearly two-thirds (65.9\%; $n=58$ ) would respect an informed refusal of treatment. A similar number would comply with a written 'Do not resuscitate' (DNR) order. In patients with no real chance of recovering a meaningful life, $81.6 \%(n=71)$ of intensivists would withhold sophisticated therapy (e.g. not start mechanical ventilation or dialysis etc.) and $75.9 \%(n=63)$ would withdraw sophisticated therapy (e.g. discontinue mechanical ventilation, dialysis etc.).

Conclusions. A combination of factors was identified as influencing the decision to admit patients to intensive care. Prognosis and disease status were identified as the main factors influencing admission. Patients with HIV/AIDS were not discriminated against in admission to intensive care.

S Afr J Crit Care 2013;29(1):28-32. DOI:10.7196/SAJCC.153

HIV/AIDS is one of the main challenges facing South Africa (SA) today. Despite having $0.7 \%$ of the world's population, SA has $17 \%$ of the world's HIV-infected people ${ }_{i}^{[1]}$ in 2010 , with a total population of 49.99 million people, ${ }^{[1]}$ an estimated $10.5 \%$ (5.24 million) were living with HIV infection. ${ }^{[1]}$ The epidemic has resulted in an increased demand for ICU beds, as a result of disease complications.

South African public hospitals are poorly resourced, overcrowded, understaffed and underfunded, with insufficient intensive care unit (ICU) beds available to meet patient demands. In 2008 - 2009, there was a total of 4719 ICU beds: $25 \%(1186)$ in the public sector and $75 \%$ (3 533) in the private sector. ${ }^{[2]}$

Although admission guidelines are available, intensivists still have to make difficult decisions in resource-limited environments with high disease burdens. These decisions are thought to be largely influenced by intensivists' personal beliefs and their knowledge of critical care ethics, with the perception that HIV/AIDS is an exclusion criterion. ${ }^{[3]}$

Intensivists need to consider four main issues when faced with a new referral to ICU: ${ }^{[4]}$ the acute condition of the patient; any pre- existing problem and co-morbidities to make ICU care unlikely to benefit the patient; whether an ICU bed is available; and if the admission would require the discharge of a current ICU patient.

The present study aimed to investigate the factors that influence South African intensivists' decisions to admit patients to ICU in a resource-limited environment and if the HIV status of the patient biases these.

\section{Materials and methods Study design}

A cross-sectional, descriptive, quantitative and analytical attitudesand-perception anonymous questionnaire survey of intensivists was conducted using convenience sampling. The study was conducted in 2011 , when the prevalence of HIV was $17.8 \%$ (5.6 million people $)^{[5]}$ and antiretroviral treatment (ART) coverage of $55 \%$ (1.3 million people). ${ }^{[5]}$

\section{Sampling strategy}

For the purpose of this study, an intensivist was defined as any specialist medical/critical nurse practitioner who practises in the 
field of critical care and who is likely to be involved in the admission of patients with HIV infection to intensivecare. This definition included specialist members of the Critical Care Society of Southern Africa (CCSSA), South African Thoracic Society (SATS), and other specialists attending a combined national conference of the CCSSA and SATS. A total of 450 questionnaires were handed out individually on registration to delegates meeting the inclusion criteria (from a total of 830 attendees recorded in the attendance register), from whom 90 questionnaires were accepted as valid and complete. The study was approved by the Biomedical Research Ethics Committee of the University of KwaZulu-Natal (BE 089/010).

An anonymous 3-part questionnaire was designed for self-completion. It included demographic characteristics and professional profiles and a survey of intensivist to admit patients to ICU. Fourteen potential determinants of admission to ICU were investigated, using 5 clinical vignettes with hypothetical patients (Fig. 1):

1. Respiratory failure in clinically advanced AIDS - older age

2. Respiratory failure in clinically advanced AIDS - younger age

3. Priority setting - one ICU bed available; HIV status and age discrepancy

4. Respiratory failure, Pneumocystis jiroveci pneumonia (PJP), AIDS-CD4 count 1 cell $/ \mathrm{mm}^{3}$; defaulted ART and tuberculosis (TB) treatment and suspected of multi-drug resistant/ extreme drug-resistant tuberculosis (MDR/XDR-TB) - possible decision on medical futility for ICU care

5. Resource limitations and priority setting; HIV status discrepancy. perceptions of what influences their decision

Specific variables in the scenarios included the last ICU bed, HIV disclosure, family wishes, withdrawing and withholding of therapy, HIV positive and possible MDR/XDR $T B$, and non-compliance with medication. These variables were drawn from the most commonly occurring factors based on personal observations.

\section{Statistical analysis}

SPSS version 19.0 (SPSS, Chicago, Illinois) was used to analyse the data. All categorical data are presented as frequency counts and percentages.

\section{Results}

Ninety of the 450 intensivists returned completed questionnaires. Table 1 indicates their gender, ages and practice profiles, with the majority (36.7\%; $n=33$ ) from KwaZuluNatal Province.

The number who stated they would respect patient autonomy as regards an informed refusal for treatment was $65.9 \%(n=58)$. A similar number would comply with a written DNR order. For patients with no real chance of recovering a meaningful life, $81.6 \%(n=71)$ of intensivists would withhold sophisticated therapy (e.g. not start mechanical ventilation or dialysis etc.); and $75.9 \%$ ( $n=63$ ) would withdraw sophisticated therapy (e.g. discontinue mechanical ventilation, dialysis etc.). The number of intensivists who cited availability of an ICU bed as influencing the decision to admit was $71.6 \%(n=63)$. Where no bed is available, the intensivist has to deliberate on withholding of care to the patient or withdrawing of care to an existing patient in ICU. In this scenario, 84.3\% $(n=70)$ would admit patients to ICU who may live for several years but whose quality of life was very poor, according to the doctor's opinion (Table 2).

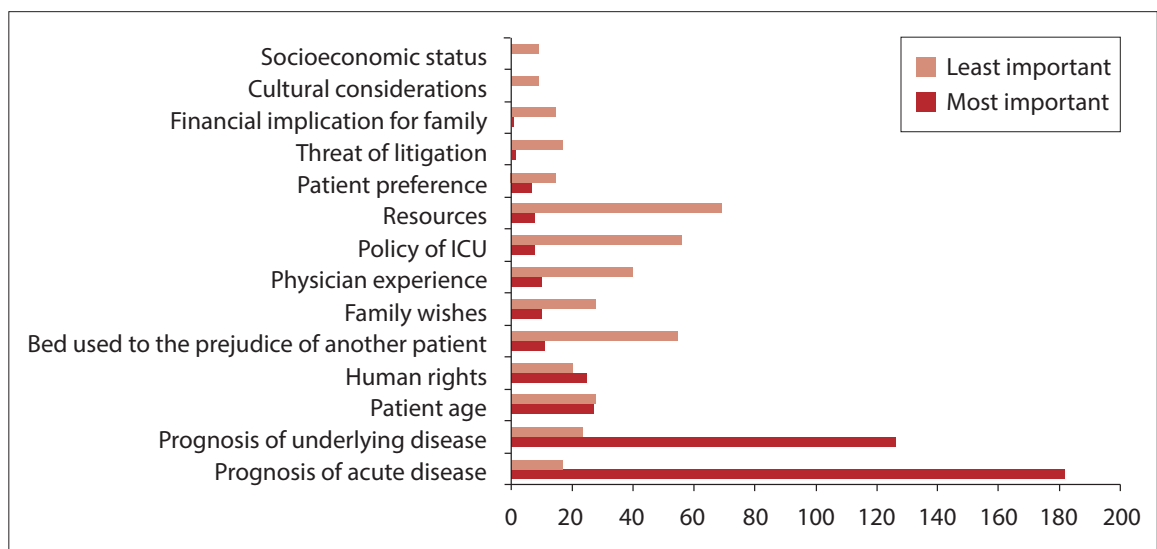

Fig. 1. Bar graph showing cumulative responses of intensivists to standardised questions regarding determinants for admission to intensive care for all 5 clinical vignettes. Dark-ochre bars represent cumulative responses that they considered most important, and light-ochre least important.

\section{Clinical vignettes of hypothetical patients}

For each of the 5 vignettes, intensivists were requested to rate admission to ICU on a Likert scale of $1-5(1=$ strongly disagree with ICU admission and $5=$ strongly agree with ICU admission). For each scenario, the cumulative dominant response is indicated in Table 3.

\section{Scenario 1: Respiratory failure in clinically} advanced AIDS - older age

A majority $(75 \% ; n=66)$ of intensivists disagreed with admission to ICU, the most important reasons given being 'prognosis of the underlying disease' $(50.6 \% ; n=41)$ and 'prognosis of the acute disease' $(37.5 \% ; n=30)$.

\section{Scenario 2: Respiratory failure in clinically advanced AIDS - younger age}

ICU admission was indicated by $60.2 \%$ $(n=53)$, the most important determinants being the 'prognosis of the acute disease' $(54.8 \% ; n=46)$ and 'prognosis of the underlying disease'(39.5\%; $n=34)$. Regarding HIV status disclosure to the spouse, $55.5 \%$ $(n=50)$ would not disclose.

Scenario 3: Priority setting - one ICU bed available; HIV status and age discrepancy In this dichotomous scenario, intensivists prioritised patient $B$ for ICU admission by $87.7 \%(n=79)$ over patient A $(10 \% ; n=9)$. If patient $A$ were already on ventilation in ICU, intensivists would not withdraw ICU care in favour of patient B, as 'the ICU physician should preserve life at all costs'. They indicated that they would admit patient $B$ to a high-care unit' $(47.7 \% ; n=42)$.

Scenario 4: Respiratory failure, PJP, AIDSCD4 count 1 cell $/ \mathrm{mm}^{3}$, defaulted ART and TB treatment and suspected of MDR/XDRTB - medical futility

Nearly $60 \%(n=50)$ of intensivists would not admit this patient to ICU, the important potential determinant to ICU care being 'limited/no hope of survival' (76.6\%; $n=69)$, the 'acute and underlying disease' $(41.5 \%$; $n=34$ ), and 'several co-morbid conditions, poor commitment to treatment and his MDR/XDR TB poses a health risk to the ICU team, patients and public in general and should be considered for palliative care $(62.2 \% ; n=56)$.

Scenario 5: Resource limitations and priority setting - HIV status discrepancy The intensivist needs to make a decision on the withdrawal of ICU care for patient $A$ in 
Table 1. Demographic characteristics of intensivists $(\mathbf{N}=90)$

\begin{tabular}{|c|c|c|c|}
\hline 1.Gender & $n(\%)$ & 2. Age (years) & $n(\%)$ \\
\hline Male & $49(54.4)$ & $<40$ & $32(35.6)$ \\
\hline Female & $41(45.6)$ & $40-49$ & $32(35.6)$ \\
\hline Total & 90 & $\geq 50$ & $26(28.9)$ \\
\hline 3. Type of hospital facility & $n(\%)$ & 4. No. of beds in hospital & $n(\%)$ \\
\hline Public regional & $16(17.8)$ & $<500$ & $37(41.6)$ \\
\hline Public tertiary & $45(50)$ & $500-749$ & $21(23.6)$ \\
\hline Private hospital & $29(32.3)$ & $\geq 750$ & $31(34.8)$ \\
\hline 5. Type of ICU bed & $n(\%)$ & 6. No. of ICU beds & $n(\%)$ \\
\hline General & $58(64.4)$ & $<7$ & $37(15.6)$ \\
\hline Surgical & $8(8.9)$ & $7-12$ & $29(32.2)$ \\
\hline Medical & $12(13.3)$ & $13-18$ & $15(16.7)$ \\
\hline Paediatric & $10(11.1)$ & $\geq 18$ & 32 (35.6) \\
\hline Coronary care & $2(2.2)$ & & \\
\hline 7. Primary specialty & $n(\%)$ & 8. Role in ICU & $n(\%)$ \\
\hline Anaesthesiology & $19(21.2)$ & Director & $14(15.6)$ \\
\hline Pulmonology & $22(24.4)$ & Senior staff & $54(60)$ \\
\hline Internal medicine/cardiology & $18(20)$ & Fellow/resident & $13(14.4)$ \\
\hline Surgery & $9(10)$ & Visiting consultant & $5(5.6)$ \\
\hline Paediatrics & $10(11.1)$ & Critical care nurse & $4(4.4)$ \\
\hline 9. Intensive care experience & $n(\%)$ & 10. Proportion of ICU time (\%) & $n(\%)$ \\
\hline$<5$ years & $27(30)$ & $<25$ & $15(16.7)$ \\
\hline $5-10$ years & $18(20)$ & $25-50$ & $24(26.7)$ \\
\hline \multirow[t]{2}{*}{$\geq 10$ years } & $45(50)$ & $50-75$ & $15(16.7)$ \\
\hline & & $>75$ & $36(40)$ \\
\hline
\end{tabular}

Table 2. Responses to various factors that influence intensivists in ethical decision-making in ICU

\begin{tabular}{|c|c|c|c|}
\hline & & Yes/no & $\%(n)$ \\
\hline 1 & Availability of an ICU bed influencing decision to admit & Yes & $71(63)$ \\
\hline 2 & Admit patients who may live for several years but with very poor quality of life & Yes & $84.3(70)$ \\
\hline 3 & Would obtain written consent for intubation and ventilation & Yes & $13.5(12)$ \\
\hline 4 & Written consent obtained for elective surgery & Yes & $97.7(86)$ \\
\hline 5 & Written consent obtained for a blood transfusion & Yes & $46.1(41)$ \\
\hline 6 & Respect for informed refusal for treatment & Yes & $65.9(58)$ \\
\hline 7 & Comply with written DNR order & Yes & $65.9(58)$ \\
\hline 8 & Withhold sophisticated therapy when no real chance of recovering a meaningful life & Yes & $81.6(71)$ \\
\hline 9 & Withdraw sophisticated therapy when no real chance of recovering a meaningful life & Yes & $75.9(63)$ \\
\hline 10 & Decision about terminal care should involve the ICU staff, the patient and the family & Yes & $65.2(58)$ \\
\hline 11 & Ethics consultant/committee can help in decisions regarding ICU admissions & Yes & $79(67)$ \\
\hline 12 & Continuing medical education programmes should include medical ethics & Yes & $91.1(82)$ \\
\hline
\end{tabular}

favour of patient $B$, or the withholding of ICU care for patient B. Intensivists prioritised patient $A$ for the continued use of the ICU bed $(81.3 \% ; n=61)$ over patient $B(18.7 \% ; n=14)$ based on the principle of 'first come, first served' (Table 3). Intensivists, in our survey, did not consider 'resources' as an important determinant to admission to ICU (Fig. 1).

\section{Discussion}

To our knowledge, this is the first survey of the attitudes and perceptions of intensivists in South Africa regarding access to intensive care for people with HIV infection. The survey found that people living with HIV/AIDS are not discriminated against in such access. Patient and family wishes were considered important determinants of decisions for admission, reflecting a departure from the traditional paternalistic medical attitude and a shift to patient self-determination and autonomy.

Apart from the nature of the presenting illness, triage decisions are also influenced by the availability of an ICU bed, which is a scarce resource. ${ }^{[6]}$ The Society of Critical Care Medicine (USA) $)^{[7,8]}$ emphasises 'benefit' as a priority, while the Bioethics Task Force of the American Thoracic Society (1997) ${ }^{[9]}$ suggests that patients should be admitted on a 'first come, first served' basis, provided 
Table 3. Clinical vignettes

\begin{tabular}{|c|c|}
\hline \multicolumn{2}{|l|}{ Scenario 1} \\
\hline Respiratory failure in clinically advanced AIDS - older age and poor functional status & $\%(n)$ \\
\hline Would disagree with admission to ICU & $75(66 / 88)$ \\
\hline Withholding therapy is preferable to withdrawing therapy & $51.7(44 / 85)$ \\
\hline \multicolumn{2}{|l|}{ Scenario 2} \\
\hline \multicolumn{2}{|l|}{ Respiratory failure in clinically advanced AIDS - young patient ( 24 years) } \\
\hline Disagree on HIV status disclosure to spouse & $55.5(50 / 90)$ \\
\hline Decision above informed by knowledge of law - yes & $75.5(68 / 90)$ \\
\hline Maximal therapy should be provided, and withdrawn if the situation becomes hopeless - agree & $56.3(49 / 87)$ \\
\hline Agree on admission to ICU & $60.2(53 / 88)$ \\
\hline \multicolumn{2}{|l|}{ Scenario 3} \\
\hline Patient A: 75 years, HIV, PJP. Priority setting - one ICU bed available & $\%$ (number agree) \\
\hline Withholding/withdrawing ventilator care to patient A - limited chance of survival & $86.6(78 / 90)$ \\
\hline Admit to ICU & $10(9 / 90)$ \\
\hline \multicolumn{2}{|l|}{ Patient B - 24 years, drug overdose, respiratory depression and seizures } \\
\hline Admit to ICU & $87.7(79 / 90)$ \\
\hline No ICU beds; maintain ICU care for patient A, admit patient B to high-care unit & $76.6(69 / 90)$ \\
\hline \multicolumn{2}{|l|}{ Scenario 4} \\
\hline \multicolumn{2}{|l|}{55 years old, respiratory failure, PJP, AIDS, CD4 count 1 cell/m³, defaulted ART and TB treatment, } \\
\hline MDR/XDR. Medically futile for ICU admission & $\%$ (number agree) \\
\hline Do not admit to ICU & $59.5(50 / 84)$ \\
\hline Limited/no hope of survival & $76.6(69 / 90)$ \\
\hline Palliative care & $62.2(56 / 90)$ \\
\hline Scenario 5 & $\%$ (number agree) \\
\hline Resource limitations and priority setting (1 ICU bed available), withold or withdraw ICU care? & to ICU admission \\
\hline \multicolumn{2}{|l|}{ Patient A: 40 years old, HIV +ve, trauma injuries, persistent vegetative state for 4 weeks, ventilator-dependent } \\
\hline \multicolumn{2}{|l|}{ Patient B: 40 years old, trauma injuries, metastatic cancer, dementia, requires ventilator support in ICU } \\
\hline Priority setting regarding prognosis: & \\
\hline Patient A: Prioritise use of ICU bed? & $81.3(61 / 75)$ \\
\hline Patient B: Very limited chance of survival (or poor prognostic index if calculated) & $88.8(64 / 72)$ \\
\hline
\end{tabular}

that there is an expected minimum benefit from ICU admission. The concept of benefit has different meanings for the intensivist, and patients and their families, that may be highly subjective and emotive.

In the USA in 2005, there were $93955^{[10]}$ ICU beds serving a total population of 313 million people; ${ }^{[11]}$ SA has 4719 beds for approximately 49 million people. The ratio of beds to population in the USA is 1:4 000, while in SA the ratio is 1:11 000, including private sector fee-for-service ICU beds. In the resource-rich USA, patients who are not admitted to an ICU because of a lack of beds are usually sent to another hospital such as those in our private sector; but unlike our public sector where they remain in the ward.

Measurable tools such as the Acute Physiology and Chronic Health Evaluation (APACHE) and Simplified Acute Physiology Scoring (SAPS) systems are inappropriate for this task as they are dependent on data accumulated during the first 24 hours of ICU care. ${ }^{[4]}$ No clear evidencebased guidelines are therefore available to assist the intensivist in deciding which patients are to be admitted to $\mid \mathrm{CU}_{{ }^{[4]}}$ particularly in the context of HIV infection in a resource-constrained environment. The present survey confirms that intensivists considered the prognosis of the acute disease $(45.7 \% ; n=38)$ and of the underlying disease $(42.2 \%$; $n=36)$ as most important.
Some surveys have suggested that intensivists seemed to make value-laden decisions based on subjective and mainly subconscious criteria. ${ }^{[12]}$ Unfair allocation of resources may result. This attitude can reflect both individual and broader Western cultural values. ${ }^{[13]}$

The majority of intensivists would keep patient A on ventilation, based on the practical principle of 'first come, first served'. This principle was also used by the intensivist in the dichotomous scenario. These decisions would mitigate against any suggestion of bias against HIV-infected patients and access to ICU care.

Age was considered important in the 2 clinical vignettes. The intensivist stated that importance given to age did not always translate into age taking preference in the hypothetical scenarios, suggesting that other variables might have influenced their decisions.

Patient or surrogate proxy preferences are unlikely to effectively limit ICU care. ${ }^{[14]}$ In a study in $1988,70 \%$ of the patients and families were willing to undergo ICU care again, even for a month of survival. ${ }^{[15]}$ Preferences were poorly correlated with functional status, or quality of life and prognosis; therefore, in this study, intensivists chose survival over quality of life.

The present survey found that most intensivists would not disclose patients' HIV status to spouses, citing 'knowledge of the law'. However, in terms of South African law, 'reciprocal third party disclosure' is 
legally permissible. ${ }^{[16]}$ A possible explanation would be a sense of duty towards the patient.

The possible effects of age and other age-associated comorbidities possibly mitigated against urgent initiation of highly active antiretroviral treatment (HAART) in the older patients.

ART use in ICU presents distinct challenges related to drug delivery, doses, drug interactions, and ARV-associated toxic effects. ${ }^{[17]}$ No consensus guidelines exist regarding the use of ARVs in ICUs. ${ }^{[18]}$ Therefore, the allocation of scarce resources, such as an ICU bed, requires difficult personal decisions by the intensivist, especially in HIV-endemic regions, on the effective triage of ICU admissions of patients with HIV infection, based on individual case presentations, availability of resources, and applicable ethical principles. ${ }^{[19]}$

In the context of HIV/AIDS, the question of survival in ICU is currently the subject of intense debate. ${ }^{[20]}$ Survival only to complete ventilator dependency, to high care and to home with a poor quality of life, compared with premorbid functioning, raises many ethical questions as to whether this level of intervention was appropriate in the first instance. ${ }^{[20]}$

Many intensivists feel that it is unethical to withhold any treatment that may potentially benefit the patient. ${ }^{[21]}$ The reality is that no healthcare system can provide all patients with all treatments available, especially if only marginal benefit is to be gained. To do so would detract from other worthy societal goals such as education or social welfare services. ${ }^{[2]}$

\section{Limitations to the present study}

The response rate of $20 \%$, while low, is the norm for questionnairebased surveys; it allowed for a 9.2\% error rate and a 95\% confidence level in reporting results. The survey did not explore intensivist factors such as religious beliefs or whether state v. private sector influenced responses to the clinical vignettes.

The discrepancies between the intensivists' decisions in practice and their answers to vignettes with hypothetical patients cannot be assessed in this study. 'Data computerization does not allow full expression of complex feelings and opinions.'[23] Notwithstanding these limitations, our findings provide a unique insight into the ethical dilemmas that face intensivists in South Africa when dealing with HIV-infected patients who seek or require intensive care.

\section{Conclusions}

A combination of factors was identified as influencing the decision to admit patients to intensive care. Prognosis and disease status were identified as the main factors influencing admission. Patients with HIV/AIDS were not discriminated against in admission to intensive care. Unrestricted access to ICU, as demonstrated in this survey, would pose major challenges to future healthcare provision for patients with HIV infection in countries with a high HIV burden, such as SA. The data may be helpful for health policymakers and ICU directors, and serve as a benchmark for future studies on ethical decision-making in the context of HIV/AIDS and ICU care in a resource-limited environment.

Authors' contributions. KN conducted the survey, interpreted the data and drafted the manuscript. JAS critically revised the manuscript for important intellectual content. UGL was responsible for the study concept and design, analysed and interpreted the data, critically revised the manuscript for important intellectual content, and supervised the overall study. All authors read and approved the manuscript for publication.

Acknowledgements. We thank Professor P M Jeena for proofreading the text for content and clarity; Ms Carrin Martin for her editing of the text; Mr Stephan van de Linde (biostatistician) for the statistical analysis; and Ms Reshania Naidoo for her expertise in formatting the figure and tables.

References

1. Statistics South Africa. Statistical release P0302-2010. http://www.statssa.gov.za/ publications/P0302/P03022010.pdf (accessed 24 February 2012).

Naidoo K, Singh JA, Lalloo UG. A critical analysis of ICU/HC beds in South Africa: 2008-2009. S Afr Med J 2013 (in press).

3. Mathiva L. ICUs worldwide: An overview of critical care medicine in South Africa. Critical Care 2002;6(1):22-23.

Levin PD, Sprung CL. Critical and Intensive Care Ethics. The Cambridge Textbook of Bioethics. UK: Cambridge University Press, 2008:432-468.

5. WHO/UNAIDS/UNICEF. Global HIV/AIDS Response: Epidemic Update and Health Sector Progress towards Universal Access 2011. http://www.who.int/hiv/pub/progress_ report2011/summary_en.pdf (accessed 1 August 2012).

6. Bhagwanjee S. Critical care in Africa. Crit Care Clin 2006;22:433-438.

7. Society of Critical Care Medicine. Guidelines for intensive care unit admission, discharge and triage. Task Force of the American College of Critical Care Medicine. Crit Care Med 1999;27(3):633-638.

8. Sprung $\mathrm{CL}$, Eidelman LA. Triage decisions for intensive care in terminally ill patients. Intensive Care Med 1997;23(10):1011-1014

9. Lanken PL, Terry PB, Adler DC, et al. Fair allocation of intensive care unit resources - Position statement by the ATS Bioethics Task Force. Am J Respir Crit Care Med 1997;156(4):12821301.

10. Halpern NA, Pastores SM. Critical care medicine in the United States 2000-2005: An analysis of bed numbers, occupancy rates, payer mix, and costs. Crit Care Med 2010;38(1):65-71. of bed numbers, occupancy rates, payer mix, and costs
[http://dx.doi.org/10.1097/CCM.0b013e3181b090d0]

11. U.S. \& World Population Clocks. http://www.census.gov/main/www/popclock.html (accessed 12 April 2012).

12. Escher M, Perneger TV, Chevrolet J-C. National questionnaire survey on what influences doctors' decisions about admission to intensive care. BMJ 2004;329(7463):425. [http:// dx.doi.org/10.1136/bmj.329.7463.425]

13. Furnham A. Factors relating to the allocation of medical resources. J Soc Behav Pers 1996;11(3):615-623.

14. Osborne M, Patterson J. Ethical allocation of ICU resources: A view from the USA. Intensive Care Med 1996;22(10):1010-1014.

15. Danis M, Patrick DL, Southerland LI, Green ML. Patients' and families' preferences for Danis M, Patrick DL, Southerland Ll, Green ML. Patients' and families' preferences for
medical intensive care. JAMA 1988;260(6):797-802. [http://dx.doi.org/10.1001/ medical intensive care.

16. McQuoid-Mason DJ, Dada MA. eds. Introduction to Medico-Legal Practice: Legal Aspects of Medical Practice. Durban: Butterworths, 2001:13-23.

17. Huang L, Quartin A, Jones D, Havlir D. Intensive care of patients with HIV infection. N Eng J Med 2006;355:173-181.

18. Morris A, Crothers K, Beck JM, Huang L. An official ATS workshop report: Emerging issues and current controversies in HIV-associated pulmonary diseases. Proc Am Thorac Soc 2011;8(1):17-26. [http://dx.doi.org/8/1/17[pii]10.1513/pats.2009-047WS]

19. Jeena PM, McNally LM, Stobie M, Coovadia HM, Adhikari MA, Petros AJ. Challenges in the provision of ICU services to HIV infected children in resource poor settings: a South African provision of
case study. J Med Ethics 2005;31(4):226-230. [http://dx.doi.org/10.1136/jme.2003.004010]

20. A critical look at critical care. Lancet 2010;376(9749):1273. [http://dx.doi.org/10.1016/ s0140-6736(10)61896-x]

21. Levinsky NG. The doctor's master. N Engl J Med 1984;311:1573-1575.

22. Truog RD, Brock DW, Cook DJ, et al. Rationing in the intensive care unit - 'The Task Force on Values, Ethics, and Rationing in Critical Care (VERRICC)'. Crit Care Med 2006:34(4):958-963.

Vincent $\mathrm{JL}$. European attitudes towards ethical problems in intensive care medicine Results of an ethical questionnaire. Intensive Care Med 1990;16(4):256-264. [http://dx.doi. Results of an ethical ques]
org/10.1007/bf01705162] 